\title{
Physiological role of growth factors and bone morphogenetic proteins in osteogenesis and bone fracture healing: a review
}

\author{
Sagalovsky S.
}

Sagalovsky Stanislav - MD, PhD, Department of Orthopedics ${ }^{1}$

$\triangle 4$ Parkstraße, Bad Lausick, 04651,

Deutschland. Tel: +49 (0) 343 45/61-761.

E-mail: s.sagalovsky@gmail.com
'Median Clinic; 4 Parkstraße, Bad Lausick, 04651, Germany

\begin{abstract}
The repair of large bone defects remains a major clinical orthopedic challenge. Bone regeneration and fracture healing is a complex physiological mechanisms regulated by a large number of biologically active molecules. Multiple factors regulate this cascade of molecular events, which affects different stages in the osteoblast and chondroblast lineage during such processes as migration, proliferation, chemotaxis, differentiation, inhibition, and extracellular protein synthesis.
\end{abstract}

A recent review has focused on the mechanisms by which growth and differentiation factors regulate the fracture healing process. Rapid progress in skeletal cellular and molecular biology has led to identification of many signaling molecules associated with formation of skeletal tissues, including a large family of growth factors (transforming growth factor- $\beta$ and bone morphogenetic proteins, fibroblast growth factor, insulin-like growth factor, vascular endothelial growth factor, platelet-derived growth factor, cytokines and interleukins). There is increasing evidence indicating that they are critical regulators of cellular proliferation, differentiation, extracellular matrix biosynthesis and bone mineralization. A clear understanding of cellular and molecular pathways involved in fracture healing is not only critical for improvement of fracture treatments, but it may also enhance further our knowledge of mechanisms involved in skeletal growth and repair, as well as mechanisms of aging. This suggests that, in the future, they may play a major role in the treatment of bone disease and fracture repair.

Key words: bone fracture healing, growth factors, bone morphogenetic protein, osteogenesis.

\section{Introduction}

Bone fractures are one of the most frequent injuries of the musculoskeletal system. Fracture repair can be considered as a biologically optimal process resulting in restoration of normal structure and function of the injured skeletal tissue. Although this process may lead to healing in the vast majority of cases, a small but significant proportion of fractures are characterized by delayed union or persistent non-union. Surgical interventions have been directed toward enhancing of fracture healing process, normalizing its rate and decreasing the likelihood of nonunion. During fracture healing, a number of growth factors, cytokines, and their cognate receptors are present at elevated levels within and around the fracture site. Many of these proteins are normally expressed in skeletal tissues, and others are released from inflammatory cells recruited to the site of injury. Induction of these proteins is regulated both spatially and temporally, suggesting that they play an active role in promoting fracture repair. The following review will summarize the current literature on the role of major cytokines and growth factors involved in fracture repair. In addition, the signaling cascades induced by these molecules will be discussed. While many cytokine and growth factor signaling events have not been specifically examined in the context of fracture healing, a large body of literature on signal transduction has emanated from studies on these molecules in embryonic bone development. Given the conserved nature of these molecules and their signaling cascades from Drosophila to humans, and taking into account similarities between the fracture repair process and embryonic bone development, it seems highly probable that these downstream signaling events are conserved in fracture repair. 

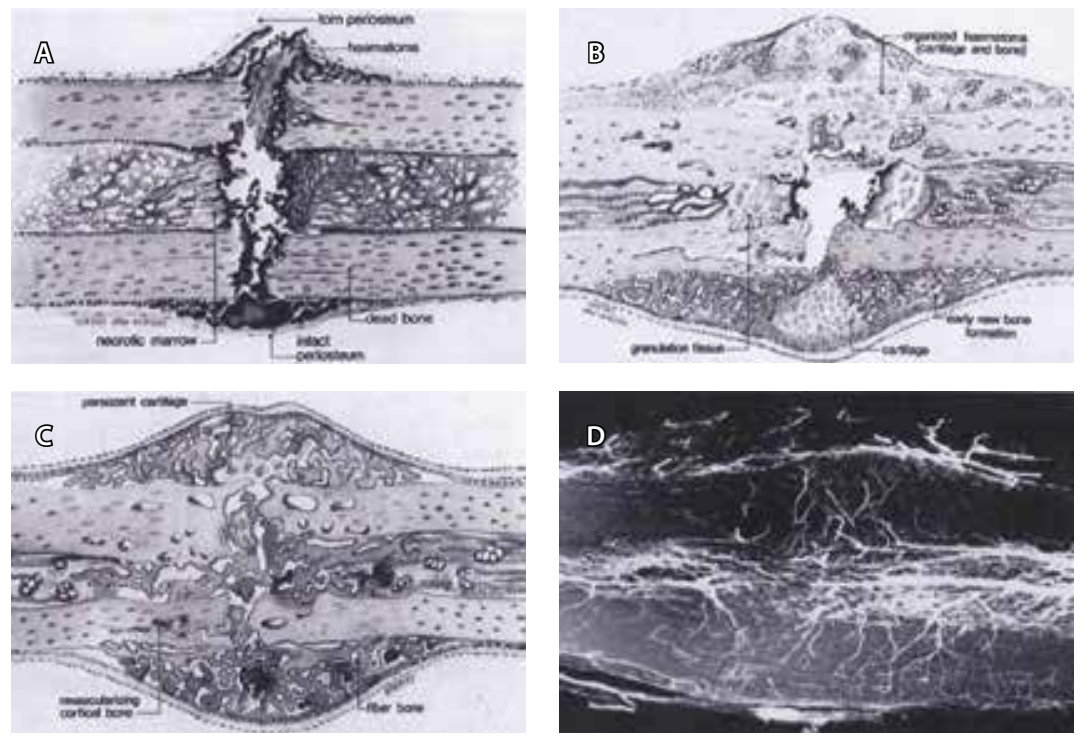

Fig. 1. Schematic representation of the stages of fracture repair

A. The first stage of fracture healing. A hematoma forms due to the ruptured vessels. There is necrotic marrow and dead bone close to the fracture line. B. During the second stage of fracture healing the callus contains granulation tissue and cartilage (and intermediate tissue types, e.g. fibrous tissue and fibrocartilage). At the cortical bone ends, new bone is formed. C. In the third stage an osseous bridge is being formed. Neovascularisation occurs in the new bone, promoting further formation of new bone. D. In the final (remodeling) stage ossified callus is remodeled and the external callus completely resorbed. The original shape and structure of the bone are restored and inside the cortex the woven bone is replaced by laminar bone

\section{General fracture healing}

Fracture healing can be envisioned as involving five distinct processes, including an immediate response to injury, intra-membranous bone formation, chondrogenesis, endochondral bone formation leading to reestablishment of local bearing function, and bone remodeling. While these processes may be discussed individually, it should be recognized that the first four of them do occur simultaneously during fracture repair and are likely to influence one another. Extensive remodeling of the newly formed bone follows these four concurrent processes and facilitates restoration of the full biomechanical integrity of the bone. A number of investigators have commented on the similarities between the repair process and embryonic bone formation $[1,2,3]$. Indeed, a number of specific events characteristic of embryonic bone formation are reiterated in fracture healing. This is especially evident as one begins to examine the specifics of local factors regulating fracture repair, specifically those involved in endochondral bone formation.

\section{The first stage after injury: acute inflammatory response}

The immediate response to injury from the fracture trauma is an initiating event of the fracture repair process. The next stage after injury is inflammation (Fig. 1A). Fracture trauma involves not only an interruption of skeletal integrity but also a disruption of the normal vascular structures and nutrient flow at and to the fracture site. This leads to reduced oxygen tension, disruption of marrow architecture and results in infiltration of inflammatory cells, macrophages, and degranulating platelets during formation of a hematoma $[4,5,6]$. While it is likely that mechanical stress, changes in oxygen tension, and loss of vascular nutrients at the fracture site may trigger some aspects of the healing, the dominant initiators of fracture repair are most likely to be numerous cytokines and multiple growth factors released into the fracture site [7]. To date, the majority of research on fracture repair has been focused on the effects of a relatively limited number of cytokines including interleukin-1 (IL-1), interleukin-6 (IL-6), tumor necrosis factor alpha (TNF- $\alpha$ ), and macrophage colony-stimulating factor (M-CSF), as well as local growth factors, such as transforming growth factor-beta (TGF-ß), bone morphogenetic proteins (BMPs), fibroblast growth factor (FGF), platelet-derived growth factor (PDGF), vascular endothelial growth factor (VEGF). The initial pro-inflammatory response involves of TNF- $\alpha$, IL- 1 and IL- 6 . These factors recruit inflammatory cells and promote angiogenesis [8]. TNF- $\alpha$ concentration has been shown to peak at $24 \mathrm{~h}$ and to return to baseline within $72 \mathrm{~h}$ after a trauma [1]. Within this time-frame, TNF- $\alpha$ is expressed by macrophages and other inflammatory cells, and it is believed to mediate its effect by inducing secondary inflammatory signals and to act as a chemotactic attractant recruiting necessary cells. TNF- $\alpha$ has been also shown to induce osteogenic differentiation of mesenchymal stem cells (MSC) in vitro. These effects are mediated by activation of two receptors TNFRI and TNFRII which are expressed on both osteoblasts and osteoclasts. However, TNFRI is continuously expressed in bones, whereas TNFRII is only expressed following injury, suggesting a more specific role in bone regeneration [9]. Among different interleukins, IL- 1 and IL- 6 are believed to be of utmost importance for fracture healing. IL-1 expression overlaps with that of TNF- $\alpha$ with a biphasic mode. It is produced by macrophages in the acute phase of inflammation, induces production of IL- 6 in osteoblasts, promotes the production of the primary cartilaginous callus, and also promotes angiogenesis at the injured site by activating either of its two receptors, ILRI or ILRII. On the other hand, IL- 6 is produced exclusively during the acute phase and stimulates angiogenesis, VEGF production, and differentiation of osteoblasts and osteoclasts [10]. 
The second stage of the bone fracture repair: recruitment of mesenchymal stem cells

In order for bone to regenerate, specific MSCs are to be recruited, proliferate and differentiate into osteogenic cells (Fig. 1B). It is not fully understood, where exactly these cells come from. Although most of data indicates that these MSCs are derived from surrounding soft tissues and bone marrow, recent research has demonstrated that a systemic recruitment of circulating MSCs to the injured site might be of great importance for an optimal healing response [11]. Which molecular events mediate this recruitment, is still under debate. It has long been suggested that bone morphogenetic protein-2 plays an important role in this recruitment, but data from [12] indicates that this is not the case. Indeed, BMP-2 is essential for bone repair [7], but other BMPs such as BMP-7 may play a more important role in recruitment of progenitor cells. Current data suggests that mesenchymal cells proliferate and differentiate into fibroblasts, chondrocytes or osteoblasts depending on biological and mechanical conditions. At each site of the fracture gap near the bone tissue, mesenchymal cells differentiate into osteoblasts producing intra-membranous woven bone. MSCs located at a larger distance from the bone tissue towards the callus center differentiate into either fibroblasts or chondrocytes. This leads to gradual stabilization of the callus.

\section{The third stage: generation of a cartilaginous and periosteal bony callus}

At the third stage of the healing process, although indirect fracture healing involves both intramembranous and endochondral ossification, the key feature of healing is the formation of a cartilaginous callus which later undergoes mineralization, resorption and is then replaced by bone (Fig. 1C). Formation of a primary hematoma is followed by formation of fibrin-rich granulation tissue [13]. Within this tissue, endochondral formation takes place in between the ends of the fracture and outside the periosteal sites. These regions are also mechanically less stable, and cartilaginous tissue forms a soft callus which ensures a stable structure for the fracture [14]. In animal models (rat, rabbit, mouse), soft callus formation peaks at 7 to 9 days after trauma, with associated peaks in both type II procollagen and proteoglycan core protein extracellular markers. At the same time, an intramembranous ossification response occurs under the periosteum, just adjacent to the distal and proximal ends of the fracture, producing a hard callus. It is the final bridging of this central hard callus that ultimately provides the fracture with a semi-rigid structure which allows weight bearing [15]. The generation of these callus tissues is dependent on MSCs recruitment from surrounding soft tissues, cortex, periosteum, and bone marrow, as well as on systematic mobilization of stem cells into peripheral blood from remote hematopoietic sites. Once these cells being recruited, a molecular cascade starts that involves collagen-I and collagen-II matrix production and participation of several peptide signaling molecules. Members of the TGF- $B$ superfamily have been shown to be of great importance for this process. The TGF- $\beta$ superfamily is involved in chondrogenesis and endochondral ossification, whereas BMP-5 and -6 have been suggested to induce cell proliferation in intramembranous ossification at periosteal sites [5]. In addition, as noted above, BMP-2 has been shown to be crucial for initiation of the healing cascade, as mice with inactivating mutations in BMP-2 are not able to form callus and do not heal their fractures successfully. Whether this is explained by the effects on MSC proliferation and differentiation, or effects on cell migration, is still under debate.

\section{Revascularization and neoangiogenesis at the fracture site}

Fracture healing requires adequate blood supply, and revascularization is essential for successful bone repair [16]. In endochondral fracture healing, this involves not only angiogenic pathways, but also chondrocyte apoptosis and cartilage degradation, as removal of cells and extracellular matrices are necessary to allow blood vessels grow into the reparation site. Once this structural pattern is achieved, vascularization is mainly regulated by two molecular pathways, namely, an angiopoietindependent pathway, and VEGF-dependent pathway [7]. Angiopoietins, primary angiopoetin- 1 and -2 , are vascular morphogenetic proteins. Their expression is induced early in the healing cascade, suggesting that they promote an initial vascular in-growth from existing vessels in the periosteum. However, VEGF pathway is considered to be a key regulator of vascular regeneration [16]. It has been shown that both osteoblasts and hypertrophic chondrocytes express high levels of VEGF, thereby promoting invasion of blood vessels and transforming vascular cartilaginous matrix into a vascularized osseous tissue. VEGF promotes both vasculogenesis, i.e. aggregation and proliferation of endothelial MSCs into a vascular plexus, and angiogenesis, i.e. growth of new vessels from already existing ones. Hence, VEGF plays a crucial role in the neoangiogenesis and revascularization at the fracture site. 
The fourth stage of fracture healing: mineralization and resorption of cartilaginous callus and bone remodeling

In order for bone regeneration to progress, the primary soft cartilaginous callus needs to be resorbed and replaced by a hard bony one. This stage of fracture healing, to some extent, recapitulates embryological bone development with a combination of cellular proliferation and differentiation, increasing cellular volume and matrix deposition. As callus chondrocytes within the callus proliferate, they become hypertrophic, while extracellular matrix becomes calcified. A cascade orchestrated primarily by a macrophage colony-stimulating factor (M-CSF), receptor activator of nuclear factor kappa B ligand (RANKL), osteoprotegerin (OPG) and TNF- $\alpha$ initiates the resorption of this mineralized cartilage [20]. During this process, M-CSF, RANKL and OPG are also thought to help recruit bone cells and osteoclasts to form woven bone. Mechanisms of calcification involve mitochondria, which accumulate calcium-containing granules generated in hypoxic environment of the fracture. After influx into cytoplasm of fracture callus chondrocytes, calcium granules are transported into extracellular matrix, where they precipitate with phosphate and form initial mineral deposits. These deposits of calcium and phosphate become the nidus for homogeneous nucleation and the formation of apatite crystals. In animal models, formation of the hard callus usually is maximal at day 14 , as assessed by histomorphometry of mineralized tissue and by measurement of extracellular matrix markers, such as type I procollagen, osteocalcin, alkaline phosphatase and osteonectin. As the hard callus formation foes on, and the calcified cartilage is replaced with woven bone, the callus becomes more and more solid and mechanically tenacious (Fig. 1D). Although the hard callus is a rigid structure ensuring biomechanical stability, it does not fully restore biomechanical properties of the normal bone. To achieve this, the fracture healing cascade initiates a second resorptive phase, aimed at remodeling of the hard callus into a lamellar bone structure with a central medullary cavity. This phase is biochemically orchestrated by IL-1 and TNF- $\alpha$, which show high expression levels during this stage, as opposed to most members of the TGF- $B$ family with a decreased expression by this time. Remodeling represents a kind of balance between resorption of the hard callus by osteoclasts and restoration of lamellar bone by osteoblasts. Although this process starts as early as at 3 to 4 weeks in animal and human models, remodeling may take years to be completed and to end up with a fully regenerated bone structure. The multiple stages of fracture healing and accompanying expression of signaling molecules are summarized in the Table. Thus, it is clear that fracture repair involves coordinate regulation of cellular chemotaxis, proliferation, and differentiation and that these events are likely to be regulated through growth factor signaling pathways (see Table). The major growth factors present in the fracture site are TGF- $\beta 1$, TGF- $ß 2$, BMP-2, BMP-3, BMP-4, and BMP-7 (OP-1), PDGF, and acidic and basic FGF-1 and FGF-2, VEGF and insulin-like growth factor (IGF) $[5,7,18,20]$. Given the well described roles of these factors in embryonic bone development and in vitro effects on bone cells, these molecules are likely to be important regulators of fracture repair $[3,6]$. Of note, the signaling pathways utilized by these molecules can be categorized into distinct groups: dependent on receptor tyrosine kinases (FGFs, PDGF, VEGFs and IGF) and dependent on serine-threonine kinase receptors (TGF-ßs and BMPs) (Fig. 2). Their common feature is signal transduction through a receptor, whose kinase activity is induced by a ligand occupying the receptor. The subtle "beauty" of such a system is a cross-talk between distinct signaling pathways and ability to further modulate the signal cascade inside the cell after initial binding with the receptor (see Fig. 2).

\section{Growth factors (FGFs, PDGF, VEGFs, and IGF) and fracture repair: regulation via tyrosine kinase receptor pathways}

\section{Fibroblast growth factors}

FGFs and their receptors (FGFRs) are known to play important roles during bone development. FGF signaling is essential for maintenance of bone homeostasis and during fracture healing. The FGF family currently includes over 20 structurally related members that bind to transmembrane tyrosine kinase receptors. Upon binding of FGFR to its extracellular ligand-binding domain, FGF causes dimerization of receptor monomers, with subsequent autophosphorylation of tyrosine residues in the intracellular signal transduction domain [21]. Alternative downstream signal transduction pathways have been described that basically imply activation of mitogen-activated protein kinase (MAPK) signaling [22]. The FGFR family consists of four distinct but highly homologous transmembrane proteins (FGFR1 - FGFR4), that interact as high affinity receptors with FGF ligands. Each full-length FGFR contains a signal peptide, three extracellular immunoglobulin-like domains, an acid box domain 
(a contiguous box of acidic residues within the linker domain between immunoglobulin 1 (Ig1) and immunoglobulin 2 (Ig2), a transmembrane domain, an intracellular juxta-membrane domain and an intracellular split tyrosine kinase domain. The third immunoglobulin domain confers specificity to FGF ligand, while the acid box makes glycosaminoglycan able to modulate the receptor at a serine residue immediately next to N-terminal of this domain. Presence of the first immunoglobulin domain (Ig1) can prevent receptor glycosaminoglycan modification through steric hindrance and inhibit signaling. Signaling involving exons, encoding the first immunoglobulin domain and the acid box, is critical for these domains to be present in mature FGFR protein. FGFs are secreted glycoproteins that are commonly sequestered in extracellular matrix by heparin sulfate proteoglycans. Heparinase or protease-cleaved FGFs stimulate a diverse array of biologic responses by binding and activating cell surface FGFRs. The major pool of FGFs bind with high affinity to FGFRs, stimulating downstream signaling only in the presence of heparin or heparin-like moieties, such as cell surface-bound heparin sulfate

Summary of 4 stages of fracture healing and associated expression of signaling molecules (based on published results from $[17,18,19]$ )

\begin{tabular}{|c|c|c|}
\hline Stage of fracture repair & Biological process & $\begin{array}{l}\text { Expression of signaling molecules and their } \\
\text { proposed functions }\end{array}$ \\
\hline \multirow[t]{3}{*}{ Inflammation } & Hematoma & $\begin{array}{l}\text { IL-1, IL-6, and TNF-a play a role in initiating the repair } \\
\text { cascade }\end{array}$ \\
\hline & Inflammation & $\begin{array}{l}\text { TGF- } ß, P D G F \text {, and BMP-2 expression increases to } \\
\text { initiate callus formation }\end{array}$ \\
\hline & Recruitment of mesenchymal stem cells & $\begin{array}{l}\text { TGF- } ß \text { response is restricted to day } 1 \text {, suggesting its } \\
\text { role in control of cellular proliferation }\end{array}$ \\
\hline \multirow[t]{4}{*}{$\begin{array}{l}\text { Cartilage formation and } \\
\text { endochondral response }\end{array}$} & $\begin{array}{l}\text { Chondrogenesis and endochondral bone formation } \\
\text { starts }\end{array}$ & $\begin{array}{l}\text { TGF-ß and BMP peak due to their involvement in } \\
\text { chondrogenesis and periosteal ossification }\end{array}$ \\
\hline & Cell proliferation in intramembranous ossification & BMP-5 and -6 rise \\
\hline & Vascular in-growth & $\begin{array}{l}\text { Angiopoietins and VEGFs are induced to stimulate } \\
\text { vascular in-growth from vessels in the periosteum }\end{array}$ \\
\hline & Neoangiogenesis & \\
\hline \multirow[t]{4}{*}{$\begin{array}{l}\text { Cartilage resorption and } \\
\text { primary bone formation }\end{array}$} & Phase of most active osteogenesis & $\begin{array}{l}\text { TNF-a rises in association with mineralized cartilage } \\
\text { resorption. This promotes recruitment of } \\
\text { mesenchymal stem cells and induces apoptosis of } \\
\text { hypertrophic chondrocytes }\end{array}$ \\
\hline & $\begin{array}{l}\text { Bone cell recruitment and woven bone formation. } \\
\text { Chondrocyte apoptosis and matrix proteolysis }\end{array}$ & $\begin{array}{l}\text { RANKL and M-CSF rise in association with resorption } \\
\text { of mineralized cartilage }\end{array}$ \\
\hline & Osteoclast recruitment and cartilage resorption & $\begin{array}{l}\text { BMP-3, }-4,-7 \text {, and }-8 \text { rise in association with } \\
\text { resorption of calcified cartilage. They promote } \\
\text { recruitment of osteoblastic lineage cells }\end{array}$ \\
\hline & Neoangiogenesis & $\begin{array}{l}\text { At this stage, BMP- } 5 \text { and }-6 \text { remain high suggesting } \\
\text { a regulatory effect on both intramembranous and } \\
\text { endochondral ossification. VEGFs are up-regulated } \\
\text { to stimulate neoangiogenesis }\end{array}$ \\
\hline \multirow[t]{2}{*}{$\begin{array}{l}\text { Secondary bone formation } \\
\text { and remodeling }\end{array}$} & Bone remodeling coupled with osteoblast activity & $\begin{array}{l}\text { IL- } 1 \text { and IL- } 6 \text { rise again in association with bone } \\
\text { remodeling, whereas levels of RANKL and M-CSF } \\
\text { go down }\end{array}$ \\
\hline & Establishment of marrow & $\begin{array}{l}\text { Diminished expression of TGF-ß superfamily } \\
\text { members }\end{array}$ \\
\hline
\end{tabular}

IL-1 - interleukin-1; IL-6 - interleukin-6; TNF-a - tumor necrosis factor alpha; TGF- - - transforming growth factor-beta; PDGF - platelet-derived growth factor; BMP - bone morphogenetic protein; VEGF - vascular endothelial growth factor; RANKL - receptor activator of nuclear factor kappa B ligand; $\mathrm{M}-\mathrm{CSF}$ - macrophage colony-stimulating factor 


\begin{abstract}
A. TYROSINE KINASE RECEPTORS (FGFR 1-5;PDGF R; IGFR 1; VEGFR 1-2)
\end{abstract}

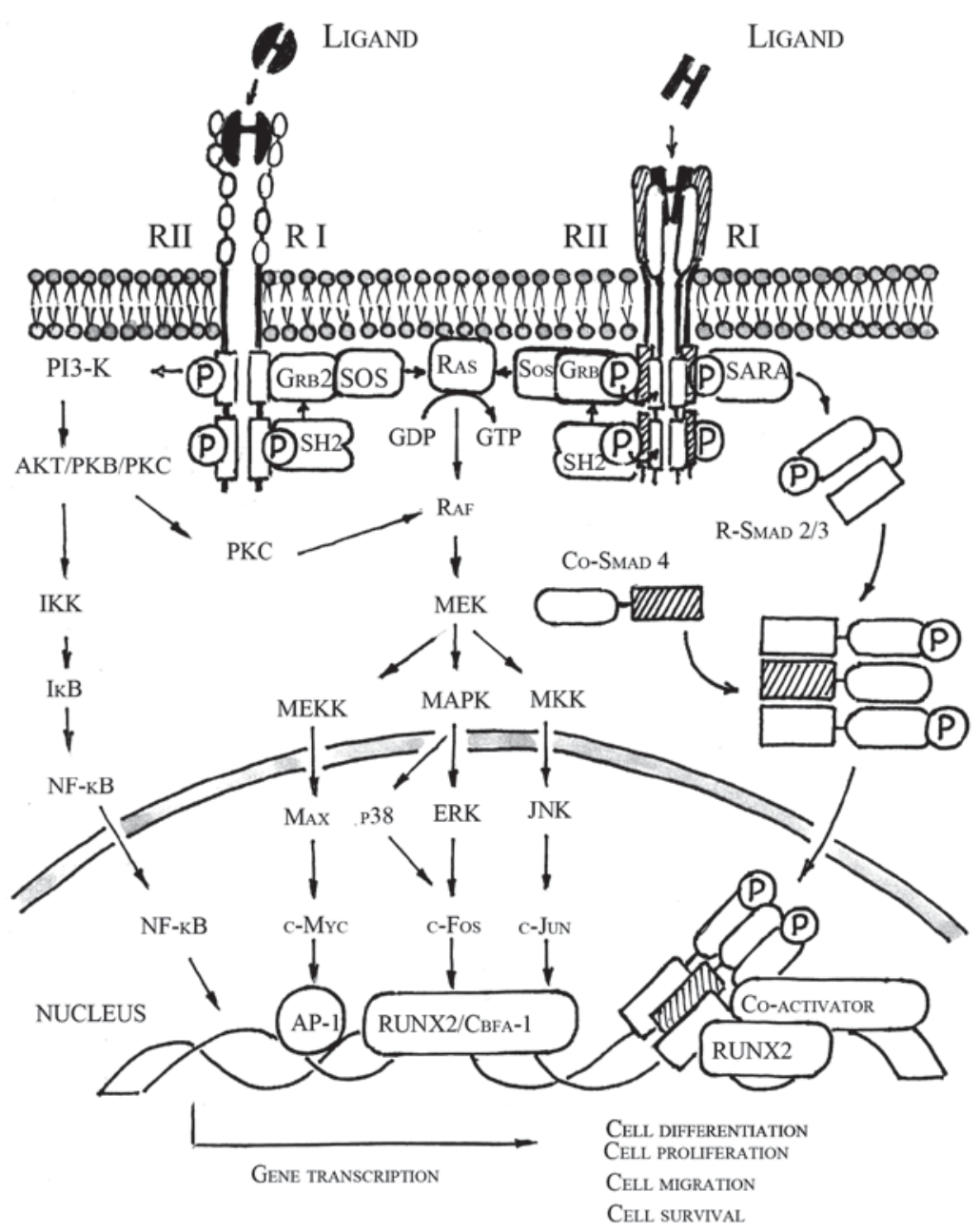

Fig. 2. Schematic presentation of major growth factors - mediated signaling pathways involved fracture repair. The picture illustrates signaling pathways downstream of tyrosine kinase receptors (A) and serine/threonine kinase receptors (B), activated by ligand-induced dimerization and initiates a cascade of events leading to protein phosphorylation and activation of nuclear proteins and transcription factors; ACT and ACTR - activin and its receptor; AP-1 - activator protein 1 is a transcription factor; AKT/PKB - serine/threonine protein kinase $B ; B M P$ and $B M P R$ - bone morphogenetic protein and its receptor; $c$-Fos - transcription factor; c-Jun - transcription factor; c-Myc - regulator gene; Co-Smad - common mediator Smad; ERK - extracellular signal-regulated kinase; FGF and FGFR - fibroblast growth factor and its receptor; Grb-2 - growth factor receptor-bound protein 2; IGF-1 and IGF-1R - insulinlike growth factor-1 and its receptor; IKB - inhibitor nuclear factor kappa B; IKK - inhibitor kappa B kinase; JNK - Jun N-terminal kinase; MAPK - mitogen-activated serine/threonine protein kinase; MEK - tyrosine/threonine kinase; MEKK - MAP 3 kinase; NF-KB - nuclear factor kappa B; p38 - p38 mitogen-activated protein kinase; PDGF and PDGFR - platelet-derived growth factor and its receptor; PI3K - phosphatidylinositol 3-kinase; PKC - protein kinase C; Raf - serine/threonine protein kinase; Ras - small guanosine nucleotide-binding protein; R-Smad - receptor-regulated Smad; RUNX2 - runt-related transcription factor 2, known as core-binding subunit alpha-1 (Cbfa-1); SARA - Smad anchor for receptor activation; SH-2 homology 2 domain proto-oncogene tyrosine-protein linase; SOS - guanine nucleotide exchange factor; TGF- $ß$ and TGF- $3 R$ - transforming growth factor and its receptor; VEGF and VEGFR - vascular-endothelial growth factor and its receptor glycoproteins, or with addition of glycosaminoglycan moieties to the receptor. Crystallographic and biochemical studies support a structural model that incorporates two FGFs with two heparin moieties and two FGFRs in symmetric complex [23]. This structure may explain why distinct heparin sulfate motifs are required to elicit activation of different FGF/FGFR pairs. Upon activation, FGFRs elicit downstream signaling via receptor dimerization, autophosphorylation and recruitment of docking and signaling proteins on the cell membrane (see Fig. 2A). FGFR1 and FGFR2 can directly bind to activate PLC, and can indirectly activate the Ras/Raf/MEK/MAPK signaling pathway [24]. Receptor autophosphorylation of tyrosine residue at position 766 in FGFR1 and 769 in FGFR2 forms a specific binding site for the SH2 domain of PLC. Activated PLC hydrolyzes phosphatidyl inositol to form diacylglycerol (DAG) and inositoltriphosphate (IP3), which, in turn, stimulate intracellular calcium release and activation of protein kinase C (PKC). Ras activation is achieved through recruitment and tyrosine phosphorylation of the docking protein Grb2, followed by binding and activation of adaptor protein SOS. MAPK activation can also be stimulated via Grb2-bound, atypical PKCs. In either scenario, MAPK activation is dependent on binding and tyrosine phosphorylation of Grb2 by the FGFR. These major downstream signaling cascades include signals generated through the Ras/ Raf (retrovirus associated DNA sequences/factors), MEK (MAP kinase kinase) and MAPK pathway (see Fig. 2A). Upon phosphorylation, MAPK translocates to the nucleus where it regulates gene expression by phosphorylation of transcription factors (RUNX2/ Cbfa-1). Both FGF1 and FGF2 can be detected in granulation tissue at the fracture site at early stages of fracture healing $[22,25]$. Macrophages and other inflammatory cells express FGFs, being the likely source of FGF in the granulation tissue. Subsequently, FGFs are expressed by mesenchymal cells, maturing chondrocytes and osteoblasts and have been demonstrated to enhance TGF- $\beta$ expression in osteoblastic cells. FGFs primarily act as mitogens on a variety of mesenchymal cells including fibroblasts, chondrocytes and osteoblasts. In the case of FGF1, mitogenic effects of this molecule appear to be exerted primarily on chondrocytes. This is suggested by the expression profile of FGF1 that peaks during chondrogenesis. In addition, FGF2 was tested in rats using a standard closed bilateral femoral fracture model. Percutaneous injection of FGF2 during the first 9 days after a fracture was associated with an increased callus size, most of which being related to increased proliferation of chondrocytes [26]. FGF2 
(basic FGF) is generally more potent than FGF1 and has attracted more attention in fracture healing studies $[22,27]$. FGF2 is expressed by osteoblasts and has also been detected in the upper hypertrophic zones of the growth plate during development, an observation that suggests their role in chondrocyte maturation and endochondral bone formation. In addition to its mitogenic and angiogenic properties, FGF2 stimulates bone resorption. These properties suggest that FGF2 has a potential to influence many phases of fracture repair, from early post-traumatic events to late remodeling of the callus [28]. This hypothesis is supported by in vivo data. In a canine tibial osteotomy model, a single injection of FGF2 was associated with an early increase in callus size [29]. This stimulation was attributed to stimulation of periosteal progenitor cell proliferation and was associated with increased mechanical strength at 16 weeks after fracture. FGF2 treatment was also associated with a more rapid resolution of the soft callus, so that at 32 weeks after a fracture, there was no difference in mechanical strength between fractures treated with FGF2 or with vehicle. In a fibular fracture model, FGF2 was injected at the time of injury into the fracture site of normal rats. Thereafter the rats were rendered experimentally diabetic via streptozotocin treatment. In these studies, FGF2 dose-dependently increased the volume and the mineral content of callus and improved mechanical properties of the healing fractures [30]. Similar results have been obtained with FGF2 suspended in a viscous hyaluronan gel, an extracellular matrix component, and given at a single dose to osteotomies generated in fibulae of baboons [31]. Unlike most other growth factors, there appears to be a positive correlation between FGF2-induced fracture callus size and mechanical strength. It is tempting to speculate that stimulation of fibroblast and osteoblast proliferation by FGF2 would result in enhanced collagen synthesis within the callus and concomitantly increase it's mechanically stability. This possibility requires further direct study.

\section{Vascular endothelial growth factor}

VEGF is a homodimeric glycoprotein that shares almost 20\% amino acid homology with a PDGF. VEGF exists in 5 isoforms resulting from alternative splicing of its mRNA, with chain lengths of 121,145 , 165, 189 and 206 amino acids [32]. These 5 forms are commonly referred to as VEGF-A, VEGF-B, VEGF-C, VEGF-D and placenta growth factor (PIGF). The various VEGF forms bind to two tyrosine kinase receptors, VEGFR-1 and VEGFR-2, which are expressed almost exclusively in endothelial cells. These receptors are characterized by the presence of seven immunoglobulin-like domains in their extracellular parts and can therefore be regarded as a new subfamily of tyrosine kinase receptors [33]. VEGF is a potent angiogenic player that has an important role during skeletal development and fracture healing. In developing mice, blocking VEGF activity results in an enlarged area of hypertrophic cartilage, loss of metaphyseal blood vessels, and impaired trabecular bone formation [34]. Thus, during development, VEGF is essential for normal growth plate morphogenesis, including blood vessel invasion and cartilage remodeling. VEGF has also been implicated in bone repair. During bone repair, VEGF is expressed in a similar pattern as that which occurs in development. Angiogenic activity of hematoma (which does not exist during development) and of plasma derived from injured individuals are related primarily to VEGF. Inhibition of VEGF activity delays bone repair in mice, decreases blood flow and leads to non-unions in rabbits [35]. Thus, during bone repair, VEGF is required not only for blood vessel formation, but also for normal callus volume and mineralization [36]. These results indicate that normal angiogenesis is central to tissue repair, and that VEGF may be the major signal to couple angiogenesis and osteogenesis during bone healing [20]. VEGF may be at least one of mediators of growth factor stimuli to bone repair in animal models and clinical trials. Most of osteoinductive growth factors, as well as ultrasound, are known to induce VEGF expression. In fact, inhibition of VEGF blocks angiogenesis induced by either FGF2 or BMP2 and induction of primary osteoblast differentiation by BMP7 (OP-1) or bone formation by BMP4. VEGF affects chemotaxis, proliferation, survival and activity of several cell types, including endothelial cells, osteoblasts and osteoclasts [35].

Consistent with the fact that endogenous VEGF is important for normal bone repair, exogenous VEGF can promote angiogenesis and bone formation in mouse femur fractures and rabbit radial critical-sized defects, being potentially synergistic with BMP4 [37]. VEGF treatment has been shown to increase bone blood flow in radial fractures and during tibial distraction osteogenesis. Finally, VEGF can increase bone formation and decrease bone resorption in intact rabbit femurs [35]. It also can stimulate endothelial cells to synthesize osteogenic factors and thus indirectly promote bone formation. In addition, osteoblasts produce VEGF and respond to it $[38,39]$. Many pro-osteogenic factors stimulate VEGF production by osteoblasts [35, 37], and VEGFR expression is regulated during osteoblast differentiation $[34,35]$. VEGF can induce osteoblast chemotaxis, proliferation, differentiation, and cAMP production. 
VEGF stimulates bone formation in organ cultures and in vivo in the duck, at least in part, due to its direct effects on osteoblasts [20,40]. Inhibition of VEGF impairs in vitro osteoblast differentiation and bone growth ex vivo [40]. VEGF can also have direct effects on bone-resorbing osteoclasts. In both wild-type and osteopetrotic (op/op) mice, VEGF regulates normal osteoclastic resorption during endochondral ossification [41], by affecting osteoclast recruitment, survival, and activity and differentiation [40]. While VEGF is likely involved in lamellar bone remodeling in mouse fractures, it may have a different role in resorption in intact rabbit femurs [37]. Inhibiting endogenous VEGF or adding exogenous VEGF can also alter cartilage tissue through effects on chondrocyte apoptosis and differentiation and cartilage resorption. These in vivo effects of VEGF on cartilage may be indirectly mediated through its stimulation of vascularization and cartilage resorbing cells. However, VEGF treatment induces phosphorylation of VEGFRs in hypertrophic chick chondrocytes, suggesting that chondrocytes may respond directly to VEGF.

\section{Platelet-derived growth factor}

PDGF is a dimeric molecule consisting of disulfidebonded A- and B-polypeptide chains. PDGF can exist either as a homodimeric (PDGF-AA, PDGF$\mathrm{BB})$ or heterodimeric form (PDGF-AB). According to relative levels of each subunit, it generates a level of ligand complexity in cells where both polypeptides are expressed [41]. Various PDGF isoforms (AA, $\mathrm{AB}, \mathrm{BB})$ exert their effect on target cells by binding with different specificity to two structurally related protein tyrosine kinase receptors (see Fig. 2A), denoted as $\alpha$ - and $ß$-receptors [41]. PDGF receptors are activated by ligand binding and subsequent receptor dimerization. As long as each subunit of dimeric PDGF molecule contains a receptor-binding site, one complete PDGF molecule binds to two receptor molecules simultaneously. The receptors also display polypeptide preference in that the a-receptor will bind either to an A-chain or B-chain, but the B-receptor only binds to B-chain. Thus, PDGF-AA induces $\alpha \alpha$ receptor dimmers, PDGF-AB induces $\alpha \alpha$ or $\alpha \beta$ receptor dimmers, and PDGF-BB induces all three possible combinations. Receptor dimerization leads to autophosphorylation, which regulates intrinsic tyrosine kinase activity. Downstream signal transduction molecules form units with activated PDGF receptor complexes through their Grb homology 2 domains (SH2) (see Fig. 2A). Molecules demonstrated as able to bind with PDGF $\alpha$-receptors and $B$-receptors include phosphatidylinositol 3 kinase, phospholipase C, the Grb/Sos family of tyrosine kinases, Ras/Raf, and signal transducer and activation of transcription MAPK/ERK pathway.

PDGF enhances DNA synthesis, increases collagen deposition, and stimulates synthesis of extracellular matrix [17]. In vitro, PDGF has been shown to stimulate type I collagen production and messenger RNA expression in osteoblasts and chondrocytes [17, 20]. PDGF has enhanced chemotactic and proliferative effects and is able to initiate differentiation of osteoprogenitor cells toward an osteoblastic lineage [5]. Platelet-growth factor functions in a macrophage autocrine feedback loop, stimulating production and release of growth factors or cytokines [7]. PDGF is initially released by degranulating platelets in the fracture-related hematoma and may be important in promoting chemotaxis [13]. At this early stage, PDGF-A is more abundant than PDGF-B, and most cells appear to produce homodimeric PDGF-AA. PDGF is also expressed by macrophages that migrate into the fracture site in response to trauma and to initial release of PDGF by platelets. Later in the process of fracture healing, PDGF protein is detectable in both early and mature hypertrophic chondrocytes, although this has been shown primarily for PDGF-A. Osteoblasts express only PDGF-B, suggesting that PDGF-BB is the primary isotype in these cells $[5,7]$. In vivo studies with exogenous PDGF/BB were done in a unilateral tibial osteotomy model in rabbits. PDGF or vehicle was suspended in a collagen carrier and injected into osteotomies. PDGF treatment was associated with a significant increase in callus density $[42,43]$. After 28 days post-surgery, PDGF-treated osteotomies were as strong as non-operated control tibiae, whereas vehicle-treated osteotomies were still weaker than controls. These PDGF effects were also associated with an earlier return to normal weight bearing. This pilot study used a small number of animals, and these promising results need further support in larger studies. The mechanisms by which exogenous PDGF might influence fracture repair have yet to be defined. K. Arvidson et al. analyzed effects of daily injections of PDGF into uninjured newborn rat femurs [17]. Their findings suggest that PDGF initiated osteogenesis and chondrogenesis processes. Daily injections of PDGF resulted in a dose-dependent increase in mesenchymal cell proliferation with a mass of new bone formation. Analysis of PDGF expression, along with $\alpha$ - and $\beta$-receptor messenger RNA, is aimed at further elucidation of its role in the inflammatory phase (days 2-4) after fracture [44]. These investigators hypothesized that the function mediated by the $ß$-receptor, including cell migration, could be a prerequisite for recruitment of mesenchymal cells at the initial step and for interaction between 
osteoclasts and osteoblasts at the bone remodeling phase. PDGF has been identified at fracture sites in humans throughout all stages of healing. Many investigators demonstrated PDGF expression in many cell types throughout a normal human healing fracture process, including endothelial and mesenchymal cells in granulation tissue and osteoblasts, chondrocytes, and osteoclasts during later stages of fracture healing $[2,7,17,20]$. One study demonstrated that PDGF actually inhibits bone regeneration induced by osteogenin (BMP3) in a rat cranial defect model [41]. The mechanism of this inhibition was attributed to significant stimulation of soft tissue repair with PDGF, which may have mitigated the effects of BMP3 on osteogenesis. These studies shed light on the potential for PDGF to influence bone formation and on its limitations in effecting the full cascade of events required for fracture repair.

\section{Insulin-like growth factor}

Growth hormone and IGF play critical roles in skeletal development and bone fracture repair. Growth hormone participates in regulation of skeletal growth and triggers IGF release in target cells. IGFs are bound to binding proteins, adding another crucial tier to modulate IGF activity. Two IGFs have been identified, namely insulin-like growth factor-1 (IGF-1) and insulin-like growth factor-2 (IGF-2); both of them are found in high concentration in serum. In bone, whilst IGF-2 is more abundant, IGF-1 may be more potent, although this might be different both between and within species. IGF-1 is a potent anabolic growth factor. IGF-1 activity is mediated by IGF type 1 receptor (IGF1R) which is a ligand-dependent tyrosine kinase receptor. Binding of IGF-1 to the IGF1R triggers autophosphorylation of its cytoplasmic kinase domain (see Fig. 2A) which activates downstream signaling pathways through interaction with various docking proteins, including the insulin-receptor-substrate-1 and Grb2. The two main signaling activated by IGF1R are Ras/Raf/ MAPK pathways. IGF-1 stimulates proliferation of osteoblast precursors and early-stage osteoblasts and promotes bone matrix formation by fully differentiated osteoblasts [19]. In vivo, endogenous and exogenous IGF has been associated with induced production of active bone matrix. IGF expression was also greatest in osteoblasts involved in active bone remodeling. This data suggests that IGF is involved in cell proliferation or differentiation of mesenchymal cells, periosteal cells, osteoblasts, and chondrocytes by way of an autocrine or paracrine fashion. Regulation of IGF is complex, and the growth hormone mode of action in skeletal cells is largely unknown. All major hormones, that regulate the skeleton, have significant effects on skeletal IGF, as do many growth factors, such as BMP-2, TGF- $\beta$ and FGF [45]. IGFs increase proliferation and play a major role in stimulating mature osteoblast function. As with other growth factors detailed in this section, osteoblasts respond to IGF signals in a way that may well depend on both the differentiation status of the cell and a cell type. At molecular level, IGF-1 upregulates the osteoblastassociated transcription factor, Osterix, but not RUNX2/Cbfa1. In addition, IGF-1, in combination with BMP-2, acts synergistically on Osterix expression [45]. Although it is widely accepted that IGFs play a decisive role in bone remodeling, their actual contribution is still unclear and needs to be understood within complex inter-relationships of IGF system components that obviously occur in vivo. Overall, the cumulative evidence suggests that major effects of IGFs are to promote late-stage differentiation and activity of osteoblasts.

A number of studies have been performed in different animal models with different doses and methods of administration, to assess the influence of growth hormone and IGF on skeletal repair. The results obtained have varied, and therefore it is still important to determine the potential role of either growth hormone or IGF in the enhancement of fracture healing. An effect of four doses of biosynthetic human growth hormone $(0.08,0.4,2.0$ and $10.0 \mathrm{mg} / \mathrm{kg} /$ day $)$ on fracture healing was studied experimentally on Wistar rats. Biomechanical tests have demonstrated increased ultimate load to failure, stiffness, and energy absorption after administration of 2.0 and $10.0 \mathrm{mg}$ doses of growth hormone. An increase in the ultimate stress to failure was only seen after a $10.0 \mathrm{mg}$ dose. The role of IGF-1 in stimulating intramembranous bone formation was studied in a calvarial defect model in rats. Experimental animals were chronically administered IGF-1 for 14 days via a subcutaneous osmotic pump. The calvarial defects that had been treated with $2 \mathrm{mg}$ of IGF-1 for 2 weeks healed by intramembranous ossification. The results of the study suggest that IGF-1 may have a role in enhancing bone formation in defects that heal via intramembranous ossification.

\section{Growth factors (TGF- $ß$ and BMPs) and fracture repair: regulation via serine- threonine kinase receptor pathways}

\section{Transforming growth factor- $\beta$}

The TGF- $\beta$ molecules are members of a large family of secreted factors collectively referred to as " TGF- $\beta$ superfamily". This superfamily contains not only 
TGF- $ß$ isoforms but also the BMPs and activins. All members of TGF- $\beta$ superfamily are synthesized as large precursors which are cleaved by proteases to yield carboxy-terminal mature protein dimers. These evolutionarily conserved molecules play important roles in cell differentiation and proliferation during development and appear to play a variety of regulatory roles in the adult organism. Five isoforms of TGF- $\beta$ have been identified to date [18]. Two isoforms, TGF- $\beta 1$ and TGF- 32 , have received the most attention regarding fracture repair and for discussion purposes may be collectively referred to as TGF- $ß$ [46]. TGF- $ß$ signaling involves two receptor types, TGF- $\beta$ receptor type I and type II (see Fig. 2B). Most cells within the fracture site as well as elsewhere in the body express TGF- $B$ receptors on their surface. Specific downstream signals are generated, and their binding to various type I receptors is associated with formation of a receptor-ligand complex. TGF- $\beta$ ligand initially binds to an oligomeric form of type II receptor followed by recruitment of a type I receptor into the complex, possibly also in an oligomeric form. This leads to formation of a heterotetrameric receptor complex associated with the ligand. The type II receptor has an intrinsic serine-threonine kinase activity, which phosphorylates the type I receptor in glycine- and serine-enriched domains, thus activating the type I receptor serine-threonine kinase. The activated type I receptor kinase is responsible for downstream transmission of the signal through the superfamily SMAD, signal effector family of molecules. Signaling through the downstream SMAD family is characteristic of TGF- $\beta$ superfamily receptors (see Fig. 2B). SMADs, a family of proteins, are important mediators in the TGF- $\beta$ signaling cascade. SMAD2 and SMAD3 are bound to cytoplasmatic SARA (SMAD anchor for receptor activation), which presents SMAD2 and SMAD3 to the activated TGF- $\beta$ receptor complex. TGF- $ß$ type I receptor then directly phosphorylates the carboxy terminal of SMAD2 and SMAD3, resulting in decreased affinity to SARA and heterotrimerization of SMAD2 and SMAD3 with SMAD4. Afterwards the entire complex is translocated into the nucleus via the nucleoporins within the nuclear pore complex, and transcriptionally regulates multiple effector genes. The presence of the SMAD2/3/4 complex within the nucleus is transient, as it becomes dephosphorylated and shuttled back out to cytoplasm, where it becomes re-phosphorylated to repeat its trip once again. In addition, several other lines of evidence point to involvement of MAPK signaling pathways in transmitting TGF- $\beta$ signals from a receptor to nucleus. In vitro kinase assays have demonstrated that TGF- $\beta$ can activate all three MAPK pathways, leading to ERK, c-Jun N-terminal kinase (c-JNK) and p38 MAPK and phosphorylation of members of the c-Jun, c- Fos, c-Myc and transcription factor families, which homo- and heterodimerize to form the activator protein (AP-1) (see reviewed in [18]). A crosstalk between SMAD and MAPK pathways adds to complexity of TGF- $\beta$ signaling. Signaling by TGF- $\beta$ family proteins regulates differentiation and function of the bone-matrix-depositing osteoblasts and of the bone-matrix resorbing osteoclasts, as well as their cross-talk between both cell types, which controls bone remodeling and homeostasis [47].

\section{Roles of TGF- $ß$ family in bone remodeling}

Bone remodeling is a complex process involving a number of cellular functions directed toward coordinated resorption and formation of new bone. Bone remodeling is regulated by systemic hormones and local factors [48]. Hormones regulate synthesis, activation, and effects of local factors that have a direct action on cellular metabolism, and they modify replication and differentiated function of osteoblast or osteoclast lineage cells. Throughout life, bone tissue is continuously remodeled by a balance between bone resorption and consecutive bone formation. Formation, deposition, and mineralization of bone tissue are executed by osteoblasts that evolve by differentiation from mesenchymal precursor cells. A key transcription factor that drives the mesenchymal precursor cell toward the osteoblast lineage and controls bone formation, is RUNX2 (Cbfa 1). The latter regulates expression of all known marker genes expressed by osteoblasts [49]. Bone resorption by osteoclasts implies demineralization of non-organic matrix by acids, with subsequent enzymatic degradation of organic matrix by cathepsin $\mathrm{K}$ and matrix metalloproteinases [50]. Osteoclasts are large, multinucleated cells of hematopoietic origin that differentiate from monocyte/macrophage precursor cells within the bone environment. Recognition of the fact, that osteoclast differentiation requires the presence of marrow stromal cells or osteoblasts, has led to discovery of two osteoblast-derived factors essential and sufficient to promote osteoclastogenesis: M-CSF and RANKL. Upon binding to their respective receptors on the osteoclast precursor cell surface (c-fms and RANK), two prominent transcription factor complexes, the NF- $\mathrm{kB}$ and NFATc-1 proteins, are activated, initiating signaling cascades essential for proper osteoclast differentiation, fusion, function, motility, and survival (Fig. 3). Osteoblasts also secrete a soluble inhibitor of osteoclast differentiation, OPG, which acts as a "decoy" receptor for RANKL. OPG 
inhibits RANK receptor activation [49]. A balance of these osteoclast-derived promoting and inhibitory signals allows calibration and coordination of bone deposition versus bone resorption [51]. A pivotal role in the bone-remodeling process has been assigned to TGF- $\beta$, because it was proven to affect both bone resorption and formation. Bone formation by TGF- $\beta$ is promoted through chemotactic attraction of osteoblasts, enhancement of osteoblast proliferation and early stages of differentiation with production of extracellular matrix proteins being part of the bone matrix, e.g. type I and II collagen, osteopontin, and osteonectin, as well as by expression of osteoblast differentiation markers, alkaline phosphatase (ALP) and, at a later stage, osteocalcin. To better understand the complex role of TGF- $B$ in bone metabolism, M. Karst et al. examined an impact of a whole range of TGF- $\beta$ concentrations on osteoclast differentiation [52]. In co-cultures of support cells and spleen or marrow osteoclast precursors, low TGF- $\beta$ concentrations stimulated and high concentrations inhibited the process of differentiation. The authors investigated the influence of TGF- $\beta$ on M-CSF, receptor activator of NF- $\mathrm{kB}$ ligand (RANKL), and OPG expression and found a dose dependent inhibition of M-CSF and RANKL expression with a dramatic increase in OPG (see Fig. 3). From their findings, they conclude that osteoclast differentiation is stimulated at low TGF- $\beta$ concentrations, because both the RANKL to OPG ratio and M-CSF levels are high. In contrast, at high TGF- $B$ concentrations, the RANKL to OPG ratio is repressed, as TGF- $\beta$ suppresses RANKL expression and increases OPG expression by the osteoblast [52]. In combination with a dose-dependent inhibition $\mathrm{M}$-CSF expression by TGF- $\beta$, this results in inhibition of osteoclast differentiation. Regarding the diversity of processes in which TGF- $\beta$ is involved, it is not surprising that this cytokine is of major importance both during embryogenesis and in maintaining bone homeostasis during life.

\section{Role transforming growth factor- $\beta$}

in bone fracture healing

TGF- $B$ are pleiotropic growth factors initially released by degranulating platelets within a hematoma and bone extracellular matrix at the fracture site [53]. At initial stages of fracture repair, TGF- $B$ can be localized immunochemically within the hard callus where it defines the region of periosteal proliferation and intramembranous bone formation. Available evidence suggests that TGF- $\beta$ are likely to be primarily involved in stimulation of proliferation by preosteoblasts in this region. In addition, expression of TGF- $\beta$ is elevated during chondrogenesis and endochondral bone formation, with an initial peak in mRNA levels around day 6 after fracture followed by a nadir at day 10 . TGF- $\beta$ expression peaks again by day 14 and remains elevated until week 4 . The nadir of TGF- $ß$ expression correlates with the peak in type II collagen expression, and the subsequent peak temporally coincides with chondrocyte hypertrophy [54]. TGF- $B$ is primarily thought to be a stimulator of undifferentiated mesenchymal cell and chondrocyte proliferation and extracellular matrix production during chondrogenesis and endochondral bone formation (see Table). TGF- $\beta$ may also be involved in normal coupling of bone formation with resorption [53]. The role of endogenous TGF- $B$ in normal fracture repair is inherently difficult to establish. However, importance of TGF- $B$ to this process is implied by ability of exogenous TGF- $\beta$ to stimulate fracture repair in several models. The ability of TGF- $ß$ to stimulate long bone healing was first demonstrated in mid-tibial osteotomies in rabbits treated with a compression plate. Continuous infusion of the osteotomy size with high doses of TGF-ß2 (1-10 $\mu$ g/day) for 6 weeks resulted in a dose-dependent increase in callus volume and increased mechanical strength, compared to untreated osteotomies. In a rat tibial fracture study, TGF- 32 (4-40 ng) was injected around the fracture site every 2 days for a 40 -day healing period. TGF- 32 dose dependently increased the cross-sectional area of the callus, and mechanical testing demonstrated a higher ultimate load in fractures treated with the high dose of TGF- 32 [55]. The results of these studies suggest that ability of TGF- $\beta$ to stimulate fracture repair may require persistent dosing or very high concentrations.

\section{Bone morphogenetic proteins}

The BMPs are a subfamily of TGF- $\beta$ superfamily of polypeptides. BMPs play critical roles in regulating cell growth, differentiation, and apoptosis in a variety of cells during development, including osteoblasts and chondrocytes. Compared to TGF- $\beta$, BMPs have more selective effects on bone and also have shown more promising results in animal models of fracture healing. BMP signal transduction occurs by a mechanism similar to other members of TGF- $\beta$ superfamily (see Fig. 2). BMP ligand can associate with several serinethreonine kinase receptors, including BMP receptor type II, receptor type IA, and receptor type IB as well as the related activin receptors (ActR-II, ActR-I) [56]. As with TGF- $\beta$, the BMP ligand binds to the type II receptor, and this receptor occupancy leads to association of the complex with an appropriate type I receptor, forming an active receptor-ligand complex. This interaction can be blocked by BMP antagonists noggin and chordin, which can bind and 


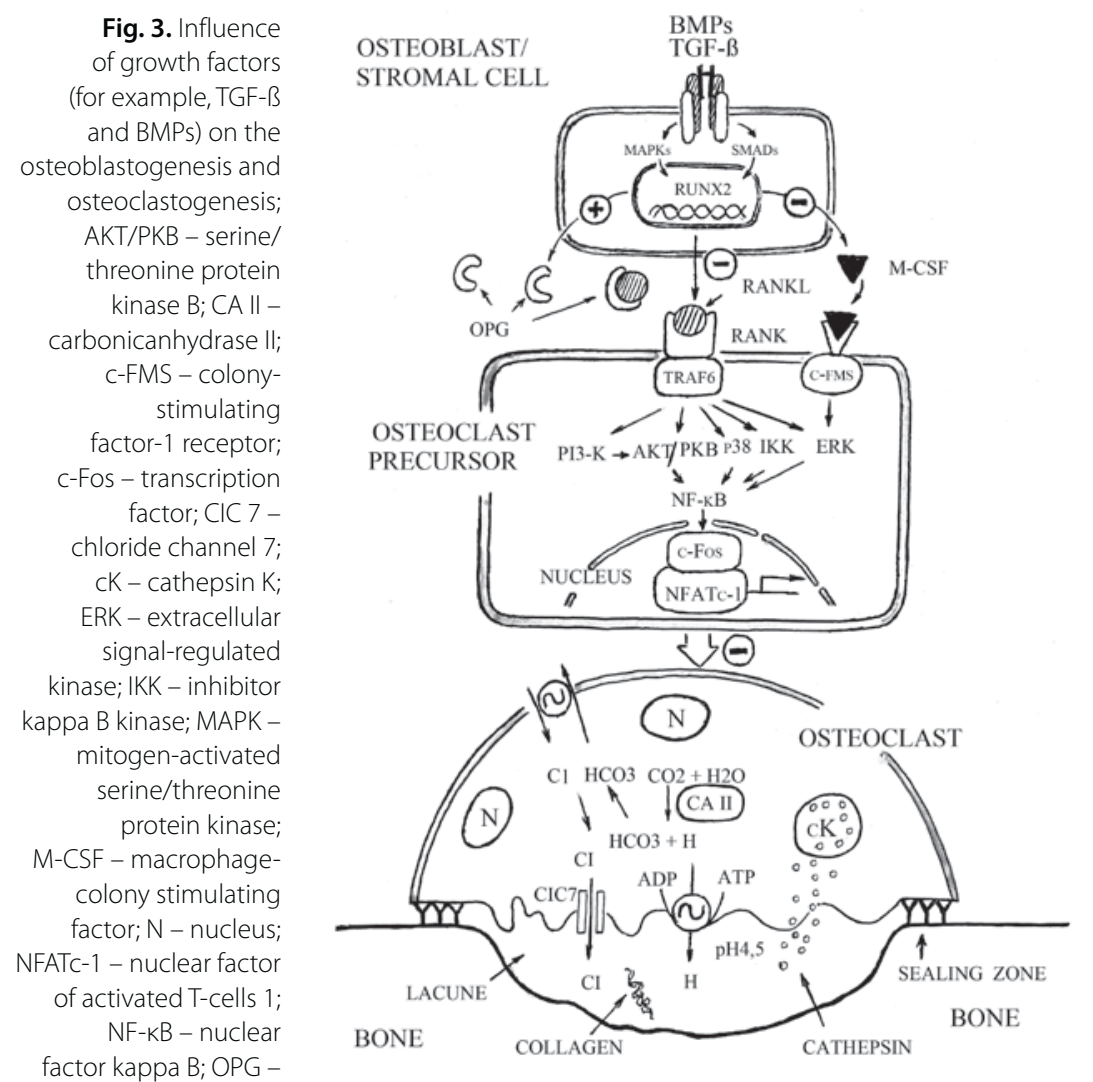

factor kappa B; OPG osteoprotegerin; p38 p38 mitogen-activated protein kinase; PI3K phosphatidylinositol

3-kinase; RANK receptor activator of nuclear factor kappa B; RANKL - receptor activator of NF-KB ligand; R-Smad receptor-regulated

Smad; RUNX2 - runt-

related transcription factor 2, known as corebinding subunit alpha-1

(Cbfa-1); TGF-ß -

transforming growth factor-ß; TRAF-6 - tumor necrosis factor receptorassociated factor-6 block BMP activity by preventing receptor binding [ 57 , 58]. This antagonist function of noggin and chordin has been specifically demonstrated in osteoblastic cells. Expression of the BMP receptors is dramatically increased in osteogenic cells of the periosteum near the ends of the fracture in the early post fracture period. Therefore, BMP signaling involves a complex receptor pattern in addition to multitude of BMPs expressed during fracture repair. BMP receptor signaling, as with the TGF- $ß s$, is transmitted through the SMAD family of signal effectors, again providing a high degree of cross-talk between signals generated by multiple members of the TGF- $ß$ polypeptide superfamily [55]. During fracture repair, BMPs reported to be expressed include BMP-2, BMP-3 (osteogenin), BMP-4 and BMP-7 (OP-1). Several reports have demonstrated that BMPs are expressed at early stages of fracture repair, when that small amounts are likely to be released from extracellular matrix of the fractured bone (see Table) [59]. During intramembranous bone formation, osteoprogenitor cells in the cambium layer of periosteum may respond to this initial low level of release from extracellular matrix and begin to differentiate. BMP-4 mRNA levels do transiently increase in osteoprogenitor cells in this region, and immunolocalization demonstrates an increase in detectable BMP-2 and BMP-4 near the fracture ends in the cambium region of the periosteum. By days 7-14 after fracture, expression of BMP-2 and - 4 is maximal in chondroid precursors, while hypertrophic chondrocytes and osteoblasts show only moderate levels of expression. The current view of the role of BMPs in fracture repair is that these molecules are primary activators of differentiation in osteoprogenitor and mesenchymal cells destined to become osteoblasts and chondrocytes (see Table). This activation by BMPs, specifically BMP-2, is inhibited by noggin and chordin which have been demonstrated to block BMP-2 interaction with its receptor [60]. As these primitive cells mature, BMP expression is dramatically reduced. BMP expression emerges transiently in chondrocytes and osteoblasts during their respective periods of matrix formation, and returns to low levels during callus remodeling. It is interesting to note that while mature osteoblasts and chondrocytes do not express significant levels of BMPs in normal bone, they both have greatly increased BMP expression later in fracture repair. A number of preclinical studies have assessed efficacy of recombinant human BMPs (rhBMPs) in the healing of critical-sized bone defects and acceleration of fracture healing $[57,59,60]$. Recombinant human BMP-2 has demonstrated efficacy in the healing of critical-sized defects in rat, rabbit, sheep, and dog models. In preclinical and human studies, rhBMP-2 has been shown to induce bone formation [59], which is integrated with surrounding bone via bone remodeling. Although the results of these preclinical studies have been promising, the corresponding high doses $(0.75-1.5 \mathrm{mg} / \mathrm{ml})$ of rhBMP, needed to induce adequate bone formation, suggest that large amounts of recombinant protein may be required to produce a clinically important effect. Multiple clinical trials in trauma surgery have provided level 1 evidence for the use of rhBMP/2 as a safe and effective treatment of fractures [60].

\section{Conclusion}

The explosion of knowledge and understanding of the role of growth factors, their mechanisms of action and molecular signaling pathways, which have been reviewed in this article, suggest the potential for many novel therapeutic targets, not only for applying growth factors but also for potential use of growth factor inhibitors or agents that target specific parts of the intracellular signaling pathways. There remains an enormous challenge to convert some of the fundamental knowledge of bone cell physiology to future therapeutically relevant techniques. We are optimistic that such novel approaches may result in real qualitative improvement of clinical outcomes beyond those currently achievable. (\$) 


\section{References}

1. Bais M, McLean J, Sebastiani P, Young M, Wigner N, Smith T, Kotton DN, Einhorn TA, Gerstenfeld LC. Transcriptional analysis of fracture healing and the induction of embryonic stem cell-related genes. PLoS One. 2009;4(5):e5393.

2. Kwong FN, Harris MB. Recent developments in the biology of fracture repair. J Am Acad Orthop Surg. 2008;16(11):619-25.

3. Tosounidis T, Kontakis G, Nikolaou V, Papathanassopoulos A, Giannoudis PV. Fracture healing and bone repair: an update. Trauma. 2009;11(3):145-56.

4. Claes L, Recknagel S, Ignatius A. Fracture healing under healthy and inflammatory conditions. Nat Rev Rheumatol. 2012;8(3):133-43.

5. Marsell R, Einhorn TA. The biology of fracture healing. Injury. 2011;42(6):551-5.

6. Yamagiwa $\mathrm{H}$, Endo $\mathrm{N}$. Bone fracture and the healing mechanisms. Histological aspect of fracture healing. Primary and secondary healing. Clin Calcium. 2009;19(5):627-33.

7. Tsiridis E, Upadhyay N, Giannoudis P. Molecular aspects of fracture healing: which are the important molecules? Injury. 2007;38 Suppl 1:S11-25.

8. Bastian O, Pillay J, Alblas J, Leenen L, Koenderman L, Blokhuis T. Systemic inflammation and fracture healing. J Leukoc Biol. 2011;89(5): 669-73.

9. Balga R, Wetterwald A, Portenier J, Dolder S, Mueller C, Hofstetter W. Tumor necrosis factor-alpha: alternative role as an inhibitor of osteoclast formation in vitro. Bone. 2006;39(2):325-35.

10. Yang X, Ricciardi BF, Hernandez-Soria A, Shi Y, Pleshko Camacho N, Bostrom MP. Callus mineralization and maturation are delayed during fracture healing in interleukin- 6 knockout mice. Bone. 2007;41(6):928-36.

11. Granero-Moltó F, Weis JA, Miga MI, Landis B, Myers TJ, O'Rear L, Longobardi L, Jansen ED, Mortlock DP, Spagnoli A. Regenerative effects of transplanted mesenchymal stem cells in fracture healing. Stem Cells. 2009;27(8): 1887-98.

12. Bais MV, Wigner N, Young M, Toholka R, Graves DT, Morgan EF, Gerstenfeld LC, Einhorn TA. BMP2 is essential for post natal osteogenesis but not for recruitment of osteogenic stem cells. Bone. 2009;45(2):254-66.

13. Kolar P, Schmidt-Bleek K, Schell H, Gaber T, Toben $D$, Schmidmaier G, Perka C, Buttgereit F, Duda GN. The early fracture hematoma and its potential role in fracture healing. Tissue Eng Part B Rev. 2010;16(4):427-34.

14. Dimitriou R, Tsiridis E, Giannoudis PV. Current concepts of molecular aspects of bone healing. Injury. 2005;36(12):1392-404.

15. Gerstenfeld LC, Alkhiary YM, Krall EA, NicholIs FH, Stapleton SN, Fitch JL, Bauer M, Kayal R, Graves DT, Jepsen KJ, Einhorn TA. Three-dimensional reconstruction of fracture callus morphogenesis. J Histochem Cytochem. 2006;54(11):1215-28.

16. Keramaris NC, Calori GM, Nikolaou VS, Schemitsch EH, Giannoudis PV. Fracture vascularity and bone healing: a systematic review of the role of VEGF. Injury. 2008;39 Suppl 2: S45-57.

17. Arvidson $K$, Abdallah BM, Applegate LA, Baldini N, Cenni E, Gomez-Barrena E, Granchi D, Kassem M, Konttinen YT, Mustafa K, Pioletti DP, Sillat $\mathrm{T}$, Finne-Wistrand $\mathrm{A}$. Bone regeneration and stem cells. J Cell Mol Med. 2011;15(4):718-46.

18. Janssens K, ten Dijke P, Janssens $S$, Van Hul W. Transforming growth factor-beta 1 to the bone. Endocr Rev. 2005;26(6):743-74.

19. Myers TJ, Yan Y, Granero-Molto F, Weis JA, Longobardi L, Li T, Li Y, Contaldo C, Ozkan H, Spagnoli A. Systemically delivered insulin-like growth factor-I enhances mesenchymal stem cell-dependent fracture healing. Growth Factors. 2012;30(4):230-41.

20. Ai-Aql ZS, Alagl AS, Graves DT, Gerstenfeld LC, Einhorn TA. Molecular mechanisms controlling bone formation during fracture healing and distraction osteogenesis. J Dent Res. 2008;87(2):107-18.

21. Marie PJ, Miraoui H, Sévère N. FGF/FGFR signaling in bone formation: progress and perspectives. Growth Factors. 2012;30(2):117-23.

22. Fei $Y$, Gronowicz G, Hurley MM. Fibroblast growth factor-2, bone homeostasis and fracture repair. Curr Pharm Des. 2013;19(19): 3354-63.

23. Coutu DL, Galipeau J. Roles of FGF signaling in stem cell self-renewal, senescence and aging. Aging (Albany NY). 2011;3(10):920-33.

24. Du X, Xie Y, Xian CJ, Chen L. Role of FGFs/FGFRs in skeletal development and bone regeneration. J Cell Physiol. 2012;227(12):3731-43.

25. Schmid GJ, Kobayashi C, Sandell LJ, Ornitz DM. Fibroblast growth factor expression during skeletal fracture healing in mice. Dev Dyn. 2009;238(3):766-74.

26. Nakajima F, Nakajima A, Ogasawara A, Moriya $\mathrm{H}$, Yamazaki M. Effects of a single percutaneous injection of basic fibroblast growth factor on the healing of a closed femoral shaft fracture in the rat. Calcif Tissue Int. 2007;81(2): 132-8.

27. Marie PJ. Fibroblast growth factor signaling controlling bone formation: an update. Gene. 2012;498(1):1-4.

28. Su N, Du X, Chen L. FGF signaling: its role in bone development and human skeleton diseases. Front Biosci. 2008;13:2842-65.

29. Kawaguchi $\mathrm{H}$. Bone fracture and the healing mechanisms. Fibroblast growth factor- 2 and fracture healing. Clin Calcium. 2009;19(5): 653-9.

30. Kidder LS, Chen X, Schmidt AH, Lew WD. Osteogenic protein-1 overcomes inhibition of fracture healing in the diabetic rat: a pilot study. Clin Orthop Relat Res. 2009:467(12): 3249-56.

31. Kempen DH, Creemers LB, Alblas J, Lu L, Verbout AJ, Yaszemski MJ, Dhert WJ. Growth factor interactions in bone regeneration. Tissue Eng Part B Rev. 2010;16(6):551-66.

32. Reumann MK, Nair T, Strachna O, Boskey AL, Mayer-Kuckuk P. Production of VEGF receptor 1 and 2 mRNA and protein during endochondral bone repair is differential and healing phase specific. J Appl Physiol (1985). 2010;109(6):1930-8.

33. Jacobsen KA, Al-AqI ZS, Wan C, Fitch JL, Stapleton SN, Mason ZD, Cole RM, Gilbert SR, Clemens TL, Morgan EF, Einhorn TA, Gerstenfeld LC. Bone formation during distraction osteogenesis is dependent on both VEGFR1 and VEGFR2 signaling. J Bone Miner Res. 2008;23(5):596-609.

34. Beamer B, Hettrich C, Lane J. Vascular endothelial growth factor: an essential component of angiogenesis and fracture healing. HSS J. 2010;6(1):85-94.

35. Maes C, Carmelit G. Vascular and nonvascular roles of VEGF in bone development. In: Ruhrberg C, editor. VEGF in Development. Austin, Texas: Landes Bioscience; 2008. p. 79-90.

36. Dai J, Rabie AB. VEGF: an essential mediator of both angiogenesis and endochondral ossification. J Dent Res. 2007;86(10):937-50.

37. Wang CJ, Huang KE, Sun YC, Yang YJ, Ko JY, Weng LH, Wang FS. VEGF modulates angiogenesis and osteogenesis in shockwave-promoted fracture healing in rabbits. J Surg Res. 2011;171(1):114-9.

38. Ogilvie CM, Lu C, Marcucio R, Lee $M$, Thompson Z, Hu D, Helms JA, Miclau T. Vascular endothelial growth factor improves bone repair in a murine nonunion model. lowa Orthop J. 2012;32:90-4.

39. Yang $Y Q$, Tan $Y Y$, Wong $R$, Wenden A, Zhang LK, Rabie AB. The role of vascular endothelial growth factor in ossification. Int J Oral Sci. 2012;4(2):64-8.

40. Roy H, Bhardwaj S, Ylä-Herttuala S. Biology of vascular endothelial growth factors. FEBS Lett. 2006:580(12):2879-87.

41. Andrae J, Gallini R, Betsholtz C. Role of platelet-derived growth factors in physiology and medicine. Genes Dev. 2008;22(10):1276-312.

42. Bordei P. Locally applied platelet-derived growth factor accelerates fracture healing. J Bone Joint Surg Br. 2011;93(12):1653-9.

43. Donovan J, Shiwen X, Norman J, Abraham D. Platelet-derived growth factor alpha and beta receptors have overlapping functional activities towards fibroblasts. Fibrogenesis Tissue Repair. 2013;6(1):10.

44. Siwicka KA, Kitoh $\mathrm{H}$, Kawasumi M, Ishiguro $\mathrm{N}$. Spatial and temporal distribution of growth factors receptors in the callus: implications for improvement of distraction osteogenesis. Nagoya J Med Sci. 2011;73(3-4):117-27. 
45. Makhdom AM, Hamdy RC. The role of growth factors on acceleration of bone regeneration during distraction osteogenesis. Tissue Eng Part B Rev. 2013;19(5):442-53.

46. Santibañez JF, Quintanilla $M$, Bernabeu $C$. TGF- $\beta /$ TGF- $\beta$ receptor system and its role in physiological and pathological conditions. Clin Sci (Lond). 2011;121(6):233-51.

47. Huang F, Chen YG. Regulation of TGF- $ß$ receptor activity. Cell Biosci. 2012;2:9.

48. Schindeler A, McDonald MM, Bokko P, Little DG. Bone remodeling during fracture repair: The cellular picture. Semin Cell Dev Biol. 2008;19(5):459-66.

49. Boyce BF, Xing L. Biology of RANK, RANKL, and osteoprotegerin. Arthritis Res Ther. 2007;9 Suppl 1:S1.

50. Sagalovsky S. Bone remodeling: cellular-molecular biology and role cytokine RANK-RANKL-osteoprotegerin (OPG) system and growth factors. Crimea J Exptl Clin Med. 2013; 3(1-2):36-44.

51. Wada T, Nakashima T, Hiroshi N, Penninger JM. RANKL-RANK signaling in osteoclastogenesis and bone disease. Trends Mol Med. 2006;12(1):17-25.

52. Karst M, Gorny G, Galvin RJ, Oursler MJ. Roles of stromal cell RANKL, OPG, and M-CSF expression in biphasic TGF-beta regulation of osteoclast differentiation. J Cell Physiol. 2004;200(1):99-106.

53. Nishimura R. A novel role for TGF- $\beta$ in bone remodeling. IBMS Bone Key. 2009;6:434-8.

54. Sarahrudi K, Thomas A, Mousavi M, Kaiser G, Köttstorfer J, Kecht M, Hajdu S, Aharinejad S. Elevated transforming growth factor-beta 1 (TGF- $\beta 1$ ) levels in human fracture healing. Injury. 2011;42(8):833-7.

55. Simpson AH, Mills L, Noble B. The role of growth factors and related agents in accelerating fracture healing. J Bone Joint Surg Br. 2006;88(6):701-5.

\title{
Физиологическая роль факторов роста и костных морфогенетических протеинов в остеогенезе и заживлении переломов кости
}

\author{
Сагаловски С.
}

Заживление переломов трубчатых костей остается главной проблемой современной ортопедии. Регенерация костной ткани и срастание перелома представляет собой сложный физиологический процесс, который регулируется множеством биологически активных молекул. Многочисленные факторы модифицируют каскад молекулярных событий, влияющий на разные стадии созревания остеобластов и хондробластов на таких этапах, как миграция, пролиферация, хемотаксис, дифференцировка, ингибирование и синтез внеклеточных белков.

В недавно опубликованном обзоре рассмотрены механизмы, при помощи которых факторы роста и дифференцировки регулируют процесс срастания костного перелома. Благодаря достижениям в клеточной и молекулярной биологии костной ткани обнаружено большое число сигнальных молекул, участвующих в формировании тканей скелета, включая большое семейство ростовых факторов (трансформирующего фактора роста $\beta$, протеинов костного морфогенеза, фактора роста фибробластов, сосудистого эндотелиального ростового фактора, инсулиноподобного фактора роста, тромбоцитарного фактора роста), а также цитокинов и интерлейкинов. Накапливается все больше доказательств того, что они являются важнейшими регуляторами процессов пролиферации и дифференцировки клеток, биосинтеза внеклеточного вещества и минерализации костной ткани. Четкое понимание клеточных и молекулярных механизмов репарации переломов очень важно не только для разработки современных методов лечения переломов, но и для углубления понимания механизмов роста и регенерации скелета, а также механизмов старения. Это позволяет предполагать, что в будущем эти знания могут сыграть одну из основных ролей в разработке методов лечения костной патологии и стимуляции срастания переломов.

Ключевые слова: заживление перелома кости, факторы роста, костный морфогенетический протеин, остеогенез.
56. Chen G, Deng C, Li YP. TGF- $\beta$ and BMP signaling in osteoblast differentiation and bone formation. Int J Biol Sci. 2012;8(2):272-88.

57. Gazzerro E, Canalis E. Bone morphogenetic proteins and their antagonists. Rev Endocr Metab Disord. 2006;7(1-2):51-65.

58. Kugimiya F, Ohba S, Nakamura K, Kawaguchi H, Chung UI. Physiological role of bone morphogenetic proteins in osteogenesis. J Bone Miner Metab. 2006;24(2):95-9.

59. Marsell R, Einhorn TA. The role of endogenous bone morphogenetic proteins in normal skeletal repair. In: Giannoudis PV, Einhorn TA, editors. Bone morphogenetic proteins: applications in orthopaedic and trauma surgery. Oxford (UK): Elsevier; 2010. p. 9-17.

60. Lissenberg-Thunnissen SN, de Gorter DJ, Sier CF, Schipper IB. Use and efficacy of bone morphogenetic proteins in fracture healing. Int Orthop. 2011;35(9):1271-80.
Сагаловски Станислав - д-р мед. наук, отделение ортопедии'

$\triangle 4$ Parkstraße, Bad Lausick, 04651, Deutschland.

Tel: +49 (0) 343 45/61-761.

E-mail: s.sagalovsky@gmail.com
'Клиника Медиан; 04651, Бад Лаузик, Паркштрассе, 4, Германия 